\title{
THE ROLE OF NON-VERBAL CUES IN IMAGE MAKING ON THE BASIS OF SELECTED PRESS ADVERTISEMENTS SHOWING ELDERLY WOMEN
}

\author{
KINGA KOWALEWSKA
}

\begin{abstract}
In Europe, the population of people over 60 years old has increased dramatically in the last few decades. Due to the demographic changes, in Poland, the world of marketing seems to discover the purchasing power of the elderly. Seniors become not only the receivers but also the senders of advertising messages. In order to sell a product, ad makers present people who are supposed to be liked, trusted, identified with and finally followed. In a press advertisement, to which an average consumer devotes 1.5 seconds, the picture is of top priority. The present research aims at analyzing the image of elderly women in press advertisements on the basis of their physical appearance, the context of the depicted situation, their clothes, facial expressions, eye-contact, and other visible traits. The survey study was conducted among young people to see the difference in their perception of elderly women in the pictures illustrating press advertisements for different products. The research results show how the positive image of the elderly in advertising can be created.
\end{abstract}

Key words: image, nonverbal communication, advertising, the elderly

\section{Image}

Image is a complex semiotic phenomenon which is ascribed to all entities in the world, from plants and animals to humans (Puppel S., 2016: 112). Creating, having and maintaining a given image is an important element of the dynamics of life (Puppel S., 2016: 110). On every level, images can be managed and serve certain functions. Due to the complex nature of the phenomenon, it can be approached from a number of perspectives; among others biological, cultural or communicative 
(Puppel S., 2016). The latter one assumes that image is an inseparable element and a result of the communication process; it is dynamic and can be intentionally shaped and regulated, and finally, it is of a dual nature, based on a dyad comprising both the presentation and the perception of the object. Image as perception should be understood as the interpretation of a person, or a thing, where the interpretation is conditioned and determined by the observer's attitudes, opinions, experience, personality traits and other features. On account of that, it can be said that image is a result of the subjective and active process of perception. As Grunig (2001: 364) put it, '[a]n image is not a picture, that is, it is not a detailed representation; it is, rather, a few details softened with the fuzziness of perception'.

\section{Image in press advertisements}

As J. Puppel (2016: 201) states: 'the essence of humans as a species and as an individual is manifested in the fact that people exist in a visual culture'. Press advertising, which is the focus of the present paper, operates solely in the visual mode of communication, fulfilling its 'adaptive rhetorical potential' in a graphic order for persuasive purposes (Puppel S., 2016: 111). One of the primary goals of marketing communication is creating the desired image. The goal is realized using, among others, press advertising, where graphic and verbal potential is used to shape the image of not only brands or products, which are promoted but also the people who are portrayed in the advertisements. As far as the perception of the visual message is concerned, research results show that the average reader devotes 1.5 seconds to a press advertisement. Considering the fact that pictures, being less structured than texts, are said to be easier and faster to read than words, it may be assumed that basically it is only the picture that is capable of being noticed and potentially remembered (Brierley, 2002: 167). Thus, many a time, the picture becomes the fundamental component of press advertisements. As for the person portrayed in a press ad picture, the image building tools may purposefully be limited to non-verbal cues arranged.

In the light of S. Puppel's (2016: 120) theory of the image, human physicality is equipped with a large set of different attributes which can be freely managed and arranged in order to create a desirable image among other individuals. Consequently, the human image is not limited to natural biological conditioning, but makes use of additional socio-cultural conditions. In press advertisement pictures, these sociocultural conditions may include, among other things, hairstyle, make-up, body ornaments, clothes, the company of others, or the place the person is portrayed in, but are also manifested by body language, including posture, gestures and facial expressions, all of which can be selected and combined in a pre-planned and intended way. 


\subsection{Gestures}

It has been said that ' $[\mathrm{h}] \mathrm{uman}$ facework and human gestures are an important part of daily communicative practice in human-human encounters' (Puppel J., 2013: $85)$. Consequently, they are equally important in the process of image making. Taking into consideration complex communicative non-verbal 'facework-gesture design' (hence FGD) (Puppel J., 2013: 85), which refers to the 'joint power of verbal, bodily and multi-modal performances' (Puppel J., 2013: 85), the perception of one's FGD gives ground for shaping the image. It is assumed that 'performance is a form of an act of display performed in front of an audience or together with an audience', which as a result produces an image - based on the presentation/perception dyad (Puppel J., 2013: 85). Although the gestural domain is significantly weaker in terms of the performativity index, the greatest performative power is achieved by a combination of facial expression and hand gestures in the facial-gestural domain. Therefore, one of the factors which are taken into consideration in the study, apart from clothes, hairstyle or the company of others, is the facework-gesture design of the presented person, where gestures are acknowledged to be 'movements of the hands, which express the inner (mental or spiritual) state of an individual' (Puppel J., 2016: 142).

The facial human domain is assumed to be 'the center of the emotionally-driven performative topography of the human body'. It owes its high communicative status to the fact that 'from time immemorial it served as a main indicator of the so called external appearance and different emotional states' (Puppel J., 2016: 201 translation is mine KK). As stated by Aldunate and Gonzalez-Ibanez (2017), who studied the role of emoticons in computer-mediated communication, 'the face is one of the most visible and complex sources of information about the emotional state of individuals' and 'in natural conditions, facial expressions and other contextual cues inform individuals about the affective states of the participants in the communication process'. In the academic discussion on the communicative properties of the face, Puppel J. (2016: 202) introduced a distinction between the 'naked' vs 'ornamented' face $(2013,2016)$. This distinction allows the face to present different types and levels of semantic indexation. A naked human face is seen as a sensitive device which is capable of expressing a universal set of emotions such as, for example, fear, joy, sadness, anger, etc. (Puppel J., 2016: 202), whereas an ornamented human face has always been used in order to enhance such universal states as aggression, defense, ecstasy, wealth, health status, age or affiliation, to name a few (Puppel J., 2016: 204). It is important to stress that ornamentation of the face is seen as highly determined by culture. Nevertheless, in any culture, whether the face is naked or ornamented, it remains the most expressive index of human emotions (Puppel J., 2011, 2013, 2016). 


\subsection{Eye-contact}

When it comes to the performativity of the human face in communicative terms, eye-contact should be mentioned first. It is acknowledged as a basic element of human interpersonal communication (Kowalewska and Puppel, 2017: 502) as 'without eye-contact people do not feel that they are fully in communication' (Argyle and Dean, 1965: 289). In the overall literature on communication, there are different functions attributed to eye-contact (Hickson, 2010). It is believed to regulate the flow of communication by signaling the beginning and end of a conversation, to facilitate and monitor feedback, as it reflects interest and attention, and, perhaps most importantly, to convey emotions. In reference to the subject matter of the current research, it should be mentioned that Kowalewska and Puppel's (2017: 502) study revealed that in the overwhelming majority of pictures from press advertisements, the actors look straight into the camera, which gives the impression of eyecontact being established. This strategy aims clearly at imitating the fundamental means of communication, which is face-to-face.

\subsection{Smile}

From among the considerable number of facial expressions which are crucial in face-to-face communication, a smile seems to be universally interpreted in a very similar way, even in different cultures. It is said to be a manifestation of positive emotions such as, for example, happiness, friendship, or warmth (Ekman, 1972; 1992). Additionally, it is strictly connected to social context as, similarly to eyecontact, 'smiling provides salient communicative signals for regulating social exchanges' (Soussignan, 2004: 178). Non-verbal communication researchers distinguish two types of smile. There is the Duchenne smile, accompanied by raised cheeks and the activation of the orbicularis oculi and zygomatic major muscles, which is considered to be a true smile, and the so called non-Duchenne smile, where the above fails to occur (i.a. Ekman, Davidson and Friesen, 1990: 351). Whether true or false, the smile not only helps judge the emotional state of a person but also influences the way the person is perceived in terms of facial attractiveness and social approachability, which constitutes a large part of the overall image of that person.

Summing up, the image of a person presented in a press ad picture is created from a considerably smaller number of elements than those of a person observed live. A picture shows a selected moment and presents it in a static way, deprived of dynamism and change, where the focus is on a single gesture or action, without its motivation or consequence. What in fact influences the image of the person presented in a press advertisement is above all physical appearance, conditioned both biologically and culturally, which includes body posture, gestures and facial expres- 
sions but also hairstyle, types of clothing or accessories, or the company of others. This fragmentary presentation of a person exemplifies what Puppel S (2016: 115) refers to as 'selective-dispersed image architecture' (translation is mine KK).

\section{Research}

The core aim of the research design was to verify how biological and sociocultural conditions influence the image of a person portrayed in a press advertisement. It was assumed that the image is flexible and dynamic, and as a consequence can be successfully managed and modified. Based on the reviewed literature, the following hypothesis was proposed: the image of a person presented in press advertisements is created on the basis of both biological and socio-cultural conditioning, and can be modified.

The present study used a diagnostic survey as a method and the questionnaire as a tool. The survey questionnaires were distributed in May 2017 among 130 university students, however 4 questionnaire forms were completed inadequately and as a result were rejected during the process of data analysis. Eventually, 126 questionnaires were taken into consideration (100\%). As far as gender representation is concerned, there were 109 (86.5\%) women and 17 men (13.5\%) with an average age of 22.

In order to make the results of the study more objective and limit the scope of the variables, it was decided that the research material should comprise only press advertisement pictures presenting elderly women. The choice was dictated by the fact that in Europe, the population of people over 60 years old has increased dramatically in the last few decades and as a result the elderly have become not only the receivers but also the senders of advertising messages. This trend is also reflected in other mass media products such as films, soap-operas, or social campaigns (Kowalewska, 2018). Nevertheless, it is worth noticing that although ad makers have begun to discover the purchasing power of the elderly, offering a wider and wider range of products designed especially for this age group, press ads for luxury or pleasure-giving goods targeted at seniors are hard to find in the Polish press (Kowalewska, 2017).

The questionnaire included 3 different pictures from original press advertisements printed in women's magazines available on the Polish press market in 2017 presenting elderly women. Before being attached to the questionnaire forms, the pictures were edited and cut so that background and written information was kept to a minimum. As a result, the respondents did not know what product or service was being advertised, which meant the answers were unaffected by product type. As the main character of interest, elderly women presented in different contexts were chosen. What all the women had in common was naturally gray hair and visible deep wrinkles, which allows them to be classified as elderly. Under each picture, a table including 20 features which could potentially be attributed to each of them was 
placed, and the respondents were asked to choose one answer for all the features for every woman in the picture. The scale ranged from +3 to -3 , where:

-+3 meant strongly agree,

-+2 -agree,

-+1 - slightly agree,

- 0 - undecided,

--1 - slightly disagree,

- - 2-disagree, and

--3 - strongly disagree.

Table 1. A table presenting possible answers in the research questionnaire

\begin{tabular}{|c|c|}
\hline nice & $+3+2+10-1-2-3$ \\
\hline kind & $+3+2+10-1-2-3$ \\
\hline caring & $+3+2+10-1-2-3$ \\
\hline cheerful & $+3+2+10-1-2-3$ \\
\hline emotional & $+3+2+10-1-2-3$ \\
\hline intelligent & $+3+2+10-1-2-3$ \\
\hline attractive & $+3+2+10-1-2-3$ \\
\hline modern & $+3+2+10-1-2-3$ \\
\hline active & $+3+2+10-1-2-3$ \\
\hline wealthy & $+3+2+10-1-2-3$ \\
\hline educated & $+3+2+10-1-2-3$ \\
\hline self-confident & $+3+2+10-1-2-3$ \\
\hline pretty & $+3+2+10-1-2-3$ \\
\hline trustworthy & $+3+2+10-1-2-3$ \\
\hline open & $+3+2+10-1-2-3$ \\
\hline lonely & $+3+2+10-1-2-3$ \\
\hline young & $+3+2+10-1-2-3$ \\
\hline well-groomed & $+3+2+10-1-2-3$ \\
\hline brave & $+3+2+10-1-2-3$ \\
\hline energetic & $+3+2+10-1-2-3$ \\
\hline
\end{tabular}

As can be seen in Table 1, the attributes in question were not only apparent features of physical appearance but also properties or traits that can only be deduced or assumed on the basis of what is seen in the picture.

In the research results, for each woman in the pictures, the top five attributes most agreed and strongly agreed as well as disagreed and strongly disagreed with were taken into consideration as the strongest markers of the woman's image. The order of respondents' answers is determined by the frequency of occurrence. 


\subsection{Research results}

In the first picture, there was a naturally looking elderly woman, grinning broadly. She was looking straight into the camera, which gave an impression of eyecontact with the reader. She was performing a self-adaptory gesture - touching her ear. She was wearing a brown top and a brownish, natural looking lipstick, so her face was partly ornamented. Her hairstyle was close to natural, with straight white hair with a medium length haircut. She was static, and no situational context was provided. In the picture, there were no other people shown and it was difficult to establish the place where the photo was taken. In persuasive terms, the indexical value of her face was enhanced by the hand.

Table 2. Features attributed to the elderly woman in the press advertisement for a dietary supplement

\begin{tabular}{|c|c|c|}
\hline Top 5 features agreed with: & & Top 5 features disagreed with: \\
& & \\
cheerful \\
nice \\
well-groomed \\
good \\
caring
\end{tabular}

The attributes with which respondents agreed most frequently was cheerful and nice (Table 2). While being cheerful could easily be seen in the facial expression of the woman, being nice was deduced from the overall impression she made upon the audience. Similarly, the woman's simple but neat hairstyle, together with a touch of a discreet lipstick could suggest that she is well-groomed. However, such properties as good and caring were ascribed to the woman solely on the basis of the intangible impression she gave. When it comes to the features most disagreed with, it was young and lonely. The fact that the woman is not young was the most apparent though. Interestingly, however, some conclusions connected with her social or family status were drawn, and she was often described as not lonely. The financial status of the woman was addressed in frequent answers not wealthy. Perhaps, it was the brown colour of her jumper and scarf, which made her described as not modern, since brown is currently perceived as old-fashioned and associated with elderly people. She was also described as not brave, which could possibly be translated into conservative. 
The second picture presented a cheerful elderly lady who was chasing after a young girl on a beach. The woman looked very natural and dynamic. She was wearing casual summer clothes in white and pink. Her face was naked, and she had no specific hairstyle. She was laughing and looking at the girl, so no eye-contact was established with the reader. Her hands were stretched towards the girl as if she wanted to catch her. The significant age difference, and the fact that the woman and the girl were apparently happy and relaxed might give an impression that the younger one is her granddaughter and the picture captures a family holiday scene.

Table 3. Features attributed to the elderly woman in the press advertisement for a painkiller

\begin{tabular}{|c|c|c|}
\hline Top 5 features agreed with: & Top 5 features disagreed with: \\
\hline $\begin{array}{c}\text { cheerful } \\
\text { caring } \\
\text { energetic } \\
\text { emotional } \\
\text { good }\end{array}$ & $\begin{array}{c}\text { lonely } \\
\text { young } \\
\text { wealthy } \\
\text { educated } \\
\text { modern }\end{array}$ \\
\end{tabular}

The context in which the woman was presented in the second picture allowed for conclusions which were more directly connected with the presented scene (Table 3). The most frequently ascribed features were cheerful and caring. The majority of the 5 most frequently occurring characteristics such as caring, energetic, emotional, and good could be deduced from the playful yet protective gestures, open body position, and facial expressions manifesting happiness and ease. Additionally, it was evident that the action taken by the woman pleased the girl and makes her happy. Probably, it was the company of the girl, which made the respondents think the woman is not lonely. On the other hand, the lack of make-up, or her natural hairstyle, together with causal clothes, could allow for describing her as neither wealthy nor modern. Interestingly, the woman gave the impression of not being educated.

In the third, mostly monochromatic picture, the upper body of an elegant looking elderly woman was presented. She was posing naked for a picture in an unspecified setting, wearing only strong make-up, with loose, long, groomed white hair. She looked rather solemn, and her pose indicated self-confidence and high selfawareness. She was static and established eye-contact, which gave an impression of 
looking down on the reader. Here, similarly to the first picture, the value of the semantic index of her ornamented face was strengthened by the hand. In the picture, she was alone.

Table 4. Features attributed to the elderly woman in the press advertisement for perfumes

\begin{tabular}{|c|c|c|}
\hline Top 5 features agreed with: & Top 5 features disagreed with: \\
\cline { 2 - 3 } $\begin{array}{c}\text { self-confident } \\
\text { wealthy } \\
\text { brave } \\
\text { modern } \\
\text { well-groomed }\end{array}$ & & $\begin{array}{c}\text { young } \\
\text { cheerful } \\
\text { trustworthy } \\
\text { nice } \\
\text { caring }\end{array}$ \\
\end{tabular}

What the respondents agreed to most frequently was the fact that the woman seemed to be self-confident and brave (Table 4). Although the woman was deprived of expensive clothes or accessories, her financial status was perceived as high (wealthy). She also made an impression of being modern and well-groomed. Both features may be attributed to the fact that elderly women traditionally avoid having long hair and wearing heavy make-up. The qualities she was denied were young and cheerful, which is evident in the picture. On the basis of her ornamented face and body language, however, some far reaching conclusions were also drawn. Namely, it was deduced that the woman is neither trustworthy nor caring. Besides, she was perceived as not nice.

\section{Final remarks}

First of all, the research results showed that the three elderly women were perceived very differently. The only attribute they were ascribed in common was not being young. Second, it is evident that physical appearance determines the perception of the person and strongly influences his or her image. Moreover, the research results show that the image of a person presented in an advertising picture is flexible and can be modified by the appropriate combination of biological and socio-cultural conditions. Of non-verbal cues, eye-contact and smiling, in particular, differentiate between a positive and negative image, whereas in both cases it is not only their presence or absence that makes a difference, but rather their quality and meaning. It 
turned out that the mere fact that eye-contact with the reader is established fails to positively influence the image, unless it is accompanied by a smile. As for smiling, it seems to be even more important in creating a positive image of a person than eye-contact itself. It seems that what additionally contributes to the overall positive image of a presented character, is the company of another person. Interestingly, the interpretation of physical appearance characteristics appears to give grounds for deductions to be made about personality traits, financial status or level of education. Above all, the study confirmed that the face and its attributes have not only the highest communicative status but also a very strong impact on overall image shaping.

\section{References}

Aldunate, N. and R. Gonzalez-Ibanez. 2017. "An Integrated Review of Emoticons in ComputerMediated Communication". Frontiers in Psychology 7. https://doi.org/10.3389/fpsyg.2016.02061

Argyle, M. and J. Dean. 1965. "Eye-contact, distance and affiliation". Sociometry 28. 289-304.

Brierley, S. 2002. The advertising handbook. $2^{\text {nd }}$ edition. London: Routledge.

Ekman P. 1992. “An argument for basic emotions”. Cognition and Emotion 6. 169-200.

Ekman, P., Davidon, R.J. and W.V. Friesen. 1990. "The Duchenne smile: emotional expression and brain physiology: II". Journal of Personality and Social Psychology 58 (2). 342-353.

Ekman, P. 1972. "Universals and cultural differences in facial expressions of emotions". In: Cole, J. (ed.). Nebraska Symposium on Motivation. Lincoln, NB: University of Nebraska Press. 207-282.

Ekman, P. 1992. "Facial expressions of emotion: new findings, new questions". Psychological Science 3(1). 34-38.

Grunig, J.E. 2001. "Two-way symmetrical public relations: past, present, and future”. In: Heath, R.L. (ed.). Handbook of public relations. Thousand Oaks, CA: Sage. 11-30.

Hickson, M. 2010. Nonverbal communication: studies and applications. New York, NY: Oxford University Press.

Kowalewska, K. 2017. "The demographic trends and the presence of the elderly in Polish press advertising in 2012 and 2016 - a comparative study". Hygeia Public Health 52 (2). 183-189.

Kowalewska, K. 2018. „Wizerunek starości i osób starszych wśród młodzieży na poziomie szkoły podstawowej”. Studium Vilnense A 15. 146-151.

Kowalewska, K. and J. Puppel. 2017. „Wizerunek i wskaźnikowość układów ciała ludzkiego w reklamie na przykładzie polskiej prasy kobiecej - badanie i uwagi wstępne”. Scripta Neophilologica Posnaniensia 17. 495-502.

Kwarciak, B. 1999. Co trzeba wiedzieć o reklamie. 2nd edition. Kraków: Wydawnictwo Profesjonalnej Szkoły Biznesu.

Puppel, J. 2011. „Uwagi w sprawie zarządzania twarzą w przestrzeni publicznej”. In: Puppel, S. (ed.). Transkomunikacja: $w$ strone sprofilowania przestrzeni publicznej jako wieloptaszczyznowej przestrzeni komunikacyjnej. Poznań: Katedra Ekokomunikacji UAM. 81-89.

Puppel, J. 2013. "Facework and gestures: a preliminary analysis of the communicative power of human performative non-verbal practices". Scripta Neophilologica Posnaniensia 13. 85-90.

Puppel, J. 2015. „Głowa człowieka jako węzeł kulturowo-komunikacyjny: uwagi w sprawie „głowy kulturowej”,.. Scripta Neophilologica Posnaniensia 15. 189-206. 
Puppel, J. 2016. “Wskaźnikowość twarzy ludzkiej: krótki przegląd problematyki”. Scripta Neophilologica Posnaniensia 16. 201-206.

Puppel, S. 2016. „Kuźnia Hefajstosa czyli krótki zarys teorii wizerunku w komunikacji człowieka”. Scripta Neophilologica Posnaniensia 16. 109-124.

Soussignan, R. 2002. "Regulatory function of facial actions in emotion processes". Advances in Psychology Research 31. 171-196. 